\section{Putting alternative medicine to the test}

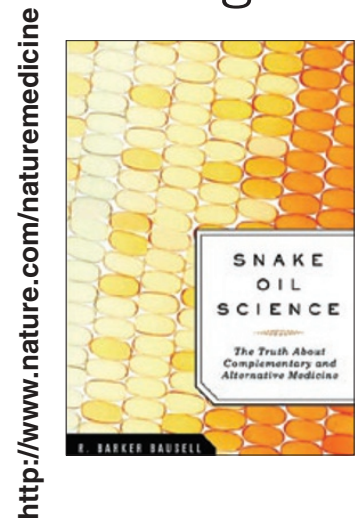

\section{Snake Oil Science: The Truth About Complementary and Alternative Medicine}

\section{R. Barker Bausell}

Oxford University Press, 2007

352 pp., hardcover, $\$ 24.95$

ISBN: 0195313682

\section{Reviewed by Brian Dolan}

Complementary and alternative medicine (CAM) is a growing market within the world of healthcare and a multibillion-dollar-a-year industry in the United States. Defining CAM is challenging-it is many different theories and methods lumped together less by internal similarities than by their general isolation from anything considered 'scientific'. Anything from hypnosis to herbal salves can be considered part of CAM, even though each derives from different theories explaining its usefulness.

In telling us the "truth" about CAM, R. Barker Bausell, professor and senior research methodologist at the University of Maryland, is concerned only with such therapies that are used with the intent of remedying a medical condition. Addressing a medical complaint rather than promoting a lifestyle is what puts the ' $M$ ' in CAM, suggests Bausell. But if such techniques are to be considered medicine, then the question Bausell poses is this: what evidence is there that they work? Most people know someone who swears by a CAM therapy to treat backache or depression, yet skeptics remain. If the person taking the CAM treatment believes it's working, then what's the problem?

The problem, according to Bausell, is that there seems to be a trend in the mainstreaming of CAM to claim that there in fact is scientific evidence of its effectiveness as a medical intervention and that this proof is derived from clinical trials. Clinical trials are the gold standard for establishing the effectiveness of a therapy - they provide much of the bedrock for evidence-based medicine. Therefore, if a CAM practitioner starts furnishing this kind of evidence to potential patients to help guide their treatment options, then it is important to look closely at how precisely these clinical trials are performed.

From the start, it is clear that Bausell is a skeptic, and throughout the book, we are told that believers in CAM are "tricked" and "hoodwinked." Therefore, one way of unveiling the truth about CAM is to explain in considerable detail how randomized clinical trials should ideally be planned and performed to illustrate the shortcomings of those who claim to provide proof of CAM's effectiveness. In fact,

Brian Dolan is at the University of California, San Francisco, 3333 California St., Suite 485, San Francisco, California 94143-0850, USA.

e-mail: dolanb@dahsm.ucsf.edu
I think that, in going into such detail, this book is very useful as an introduction to clinical trial design for students. Bausell's qualifications here are well suited, as he was formerly Research Director of a US National Institutes of Health-funded CAM Specialized Research Center, where he oversaw and analyzed clinical trial design. It may be an unintended consequence of his prolonged meditation on the complications and challenges to good randomized clinical trial design that one gains a sense that almost no clinical trial is any good. "And as bad as this situation is in conventional medicine," says Bausell, "it is far worse in CAM." However, it is not exactly clear from his logic why it is "far worse" for CAM than for conventional medicine, when it seems that most of the conditions that weaken clinical trials apply equally to whatever one is trying to test.

But this is purportedly a book about CAM, and the list of bad clinical trials relating to it must be so long that the author chooses to look closely at only a few. To prove his point that there is actually no sound scientific evidence that CAM works, Bausell summarizes the results of a couple dozen "high-quality" clinical trials, the vast majority of which offer no positive findings.

Yet patients nevertheless believe that they feel better after a CAM treatment. Bausell does not dispute that such people "believe" they feel better, but he argues that the principal reason for their misjudgment is that they underestimate the power of persuasion. This is also why people who are enrolled as subjects in clinical trials will report feeling better even though they were administered a placebo rather than the experimental therapy.

Therefore, Bausell is equally concerned to tackle the puzzle of the 'placebo effect'. It is important for his argument that CAM be considered as much like a placebo as possible, which he defines as "a pharmacologically inactive substance that can have a therapeutic effect if administered to a patient who believes that he or she is receiving an effective treatment." With a rhetorical sleight of hand, Bausell asserts by analogy that CAM treatments are "pharmacologically inactive substances" and is not concerned here with what claims, if any, CAM practitioners make to having biomedical knowledge about properties that could affect one's physiology. They do not matter, Bausell wants his readers to believe, because if he can demonstrate why placebos (which by design are truly 'fake' therapies) seem to work, then it will satisfy the loose end as to why anyone would believe that CAM works (regardless of its physical properties). Although it is directly related to his exposition on clinical trial design, in which poorly controlled placebos create bad results, the argument that Bausell makes is that a person's belief in his or her improvement can be rationalized as a conditioned response to his or her desires and expectations. It is possible that he also intends to imply that his analysis of the placebo effect actually proves that CAM works in this way and only in this way.

So who will be convinced by this presentation of the "truth"? For those many people who pursue CAM less for the ' $M$ ' and more for the ' $A$ ', it seems unlikely that analyzing it all according to the design of clinical trials will make one iota of a difference. But for ethically minded individuals who consider truth in advertising to be an important area of study in the ever-booming market for medical merchandise, any scrutiny of claims for evidence-based CAM would be well informed by this book. 